\title{
Research on Development Trend of Condemned General Ammunition Destruction
}

\author{
Qi Wang ${ }^{\text {a }}$, Xihui Mu, Liangchun Li and Xiaoming Lv \\ Shijiazhuang New Technology Application Institute, Shijiazhuang 050003, China \\ a472783995@qq.com
}

\begin{abstract}
Keywords: condemned general ammunition, ammunition destruction, ecological civilization construction, development trend.
\end{abstract}

\begin{abstract}
Condemned general ammunition destruction is the terminal and important part of the ammunition life-cycle management. Firstly, the new demands of condemned general ammunition destruction for constructing "Beautiful China" are described in several aspects, such as safety protection, ecological civilization construction, the use of renewable resources, intelligence destruction and so on. Then, the development trend of condemned general ammunition destruction based on requirements of safety, environmental protection, economy and technology is analyzed.
\end{abstract}

\section{Introduction}

Condemned general ammunition destruction is the terminal part of the ammunition life-cycle support and the whole process management ${ }^{[1]}$. With the rapid development of science and technology and the progress of social civilization, especially since the concept of "Beautiful China" gradually accepted universally, condemned general ammunition destruction is facing to unprecedented situations and challenges. It's meaningful to explore and grasp the development trend of condemned general ammunition destruction actively to promote the scientific development in the work of condemned general ammunition destruction.

\section{The Situation of Condemned General Ammunition Destruction}

\subsection{The Requirements of Safety Protection.}

Safety is not always only the first principle for the work of condemned ammunition destruction, but also the basic requirement throughout the whole process of condemned ammunition destruction. With the new type ammunition entering into the end of life successively, especially the ammunition such as cluster bombs, fuel air explosive and penetrators with new structures, new principles and new technology, the recent work of destruction is enriching the connotation of safety protection on the basis of preventing fragment and shock hazards. There are new and higher requirements in setting of safe distance, safety design of operating equipment, safety protection of operating personnel, safety inspection of operating processes, safety risk assessment, and so on ${ }^{[2-3]}$.

\subsection{The Requirements of Ecological Civilization Construction.}

China brings ecological civilization construction into overall layout of Socialism with Chinese characteristics which requires that condemned ammunition destruction should respect nature, protect nature and be in harmony with nature. In a long time, in spite of those about taking into account the environmental processing requirements, using the corresponding environmental protection measures and developing methods related to environmental protection in condemned general ammunition destruction practice, there has been still about $10 \%$ of the ammunition destructed by the way of burning and bombing destruction. The extensive and backward way of burning and bombing destruction whose environmental protection lever is relatively low is incompatible to the requirement of constructing ecological civilization and building environment-friendly society. It hampers the progress of constructing "Beautiful China" which is bound to be dealt with as soon as possible. 


\subsection{The Requirements of Renewable Resources Use.}

Currently, the problems such as the sharp reduction of global natural resources, the increased difficulty of accessing to high-quality raw materials and the increasingly severe situation of resource constraints require to increase the kinds of renewable resources in condemned ammunition destruction and the depth of recycling in order to ease the contradiction between the tight resource constraints and the growing economic development demand. As we all know, condemned ammunition contains a wealth of metal, nonmetal, energetic materials and other resources. How to achieve the fine dismantling of condemned ammunition, how to expand the recycling way of resources and how to make the recyclable resources play an important role in their surplus value are a necessary requirement for condemned ammunition destruction to build a resource-saving society in the near future.

\subsection{The Requirements of Intelligent Destruction Technology.}

Technology is an important guarantee to accomplish the condemned ammunition destruction efficiently. Traditional semi-mechanized and mechanized equipment for destructing condemned ammunition effectively meet the needs of large volumes of old type ammunition destruction to some extent. However because of the change in structural characteristics, process characteristics and material properties of the new type ammunition, the destruction process becomes more complex. The operation means demand becomes more intense. The operation visualization standard becomes higher and the operation strength becomes stronger. It's difficult to meet the demand of large quantities of the new type ammunition destruction relying on existing destruction processing equipment at present. The current situation puts forward a new request for intelligence and automation of condemned ammunition destruction ${ }^{[4]}$.

\section{The Development Trend of Condemned General Ammunition Destruction}

\subsection{Based on Safety Requirements, Strengthen Researches on Safety Theory and Protection Technology.}

Aiming at the serious safety issues of condemned ammunition destruction, research on the safety risk assessment theory and methods of condemned ammunition destruction should be carried out. Safety risk assessment methods are adapted to condemned general ammunition destruction institutions covering the whole process and all aspects. The methods must objectively reflect the safety risk status of condemned ammunition destruction which would be easy to be understood, grasped and operated. The methods can standard the assessment procedures of the safety risk assessment to avoid or reduce security risks. And it can improve the ability of safety precaution to prevent accidents and improve safety decision-making lever. According to the safety needs of new type ammunition technical support, researches on anti-fragment, anti-shock, anti-metal jets, anti-static, anti-virus, anti-ray radiation and other safety protection techniques must be strengthen. Large-caliber ammunition, cluster bombs, fuel air explosive and other new type ammunition maintenance and destruction operation criterion should be proposed. Applied research on ammunition technical support and safety protection of new materials and structures should be carried out. It's necessary to increase the intensify of ammunition whole process safety management and promote the use of condemned ammunition cartridge and projectile disfigurement technology in order to destroy physical structures, lose military capabilities and eliminate military color.

\subsection{Based on Environmental Requirements, Carry Out Researches on Green Destruction Methods.}

According to the requirements of environmental protection and ecological civilization, it's time to strive to carry out green destruction technologies such as "explosives - solid propellant - projectile" burning and bombing controlled, TNT melt and atomization burning, TNT wastewater treatment, low temperature embrittlement destruction, laser remote detonation destruction, ammunition destruction "three wastes" (waste gas, waste water, waste residue) fast detection online, safe processing and so $\mathrm{on}^{[5-7]}$. It is imperative to accelerate the transformation of destruction operations and reduce the amount of burning and bombing destruction outdoors and emissions of "three wastes" during 
ammunition destruction process. The problem of low environmental protection lever of burning and bombing destruction should be solved to build environment-friendly mode of condemned ammunition destruction. Aiming at the fact that demilitarization ammunition equipment can not adapt to the new type ammunition destruction at present, the high-tech ammunition destruction technology should be transferred on the basis of updating traditional condemned ammunition destruction technology. Application integration and technological innovation would be taken in the aspects such as intelligent control, safety protection, environmental processing, visible surveillance, ergonomics, appearance design and so on. The intelligent, automated and serialized level of the new generation demilitarization ammunition equipment should be improved according to the requirements of "reserve one generation, develop one generation, product one generation".

\subsection{Based on Economic Requirements, Deepen the Recycling of Renewable Resources.}

On the basis of combining benefit, finer decomposition, intensive dispose and deep utilization must be paid attention. Visible disassembly constraint technology can be applied to judging disassemble logic, refining technological process and increasing the depth of disassembly. Engineering researches on condemned ammunition destruction energetic materials and projectile separation technology, metal materials and non-metallic materials separation technology as well as recycling value should be continue to developed. The explosion properties and collective energy of the waste energetic materials and can be made full use of. It needs to promote to explore the technology of RDX explosive components processing diamond, propellant rods, propellant ignition energy, propellant and explosives to be able to become fertilizer in order to further enhance the utilization efficiency of waste energetic materials. The performance of condemned ammunition component parts should be assessed scientifically. The depot recycling mechanism of ammunition component parts, especially tungsten penetrator core, long-range rockets ammunition gyroscopes and other new high-value component parts must be studied to bring ammunition component parts with superior performance, high value and complex process into remanufacture and reproduction process to achieve the purpose of saving and recycling resources.

\subsection{Based on Technological Requirements, Make Good Comprehensive Demonstration of New Type Ammunition Destruction.}

Because high-tech ammunition has the diversifications of structural forms, metal materials, constraint forms and function, the ammunition types and classification principles must be confirmed base on the trinity of "check - maintenance - destruction" first of all. Then, the destruction quantities prediction of high-tech ammunition should be carried out. The technology engineering application of laser cutting, closed-end burning controlled, flexible thin-walled projectile clamping and narrow space bullet fuse turning off would be demonstrated ${ }^{[8]}$. It's requisite to strive to develop the front tracking, test exploration and comprehensive demonstration of high-tech ammunition such as cluster bombs, FAE, long-range rockets and energetic materials such as the overall placement propellants and high-energy mix of explosives. Researches on logic relationship visualization of condemned ammunition disassemble must be strengthen ${ }^{[9]}$. The reverse assembly, logical judgment, constraint changes and other factors to determine a reasonable destruction processes route should be considered comprehensively. It can provide decision support to grasp the key issues on the high-tech ammunition destruction globally, to plan the high-tech ammunition destruction and to guide scientific research on high-tech ammunition.

\section{Summary}

Condemned general ammunition destruction is the terminal and important part of the ammunition life-cycle management. At this stage, in order to do well in condemned general ammunition destruction, the urgency situation faced to must be grasped and the advanced destruction technologies must be developed and applied. On the basis of ensuring the destruction safety and destruction efficiency, green destruction must be developed rapidly to adapt to the new requirements of ecological civilization construction and achieve the great goal of building "Beautiful China". 


\section{References}

[1]. Li J M, Lei B, Ding Y K. Technology of conventional ammunition disposal. National Defense Industry Press, 2012.

[2]. Cao H Q, Liu W B, Bai D L. Safety protective measure of waste ammunition disposal. Value Engineering. Vol.31 (2012) No.28, p. 320-321.

[3]. Li J M, Gao X B, Ding Y K. Safe Measure During Waste Ammunition Disposal Work. Blasting. Vol.28 (2011) No.3, p. 116-118.

[4]. Liu P, Zhang H Z, Jin C G, et al. Overview on the technology of blasting destruction abandoned ammunition. Engineering Blasting. Vol.17 (2011) No.1, p. 86-89.

[5]. Zhang H X, Liu P, Cao H A, et al. Study on the Treatment of Waste Gas Environmental Pollution in Abandoned Ammunition Burning. Industrial Safety and Environmental Protection. Vol.37 (2011) No.12, p. 32-34.

[6]. Hao J X, Hao J, Zhang X P. Design of TNT melting atomization combustion system. Journal of Sichuan Ordnance. Vol. 35 (2014) No. 2, p. 67-69.

[7]. Xia F J, Song G F, Xiao D S, et al. Research on development thoughts of green harmless disposal technology for condemned ammunition. Ordnance Industry Automation. Vol. 30 (2011) No. 5, p. 94-96.

[8]. Huang $\mathrm{P} \mathrm{B}$, Zhang $\mathrm{H} \mathrm{Z}$, Xie Q M, et al. Review on destruction technology of rejected conventional ammunition. Engineering Blasting. Vol.19 (2013) No.6, p. 53-56.

[9]. Li J M, Ke Y, Gao X B. Discussion on the waste ammunition disassembling disposal for safety and environmental protection. Value Engineering. Vol.30 (2011) No.4, p. 195-196. 